\title{
Oficinas de fanfictions na escola: investigando práticas de revisão e reescrita
}

\author{
Larissa Giacometti Paris \\ Universidade Estadual de Campinas (UNICAMP), Campinas, São Paulo, Brasil \\ larissagparis@gmail.com
}

DOI: http://dx.doi.org/10.21165/el.v45i2.587

\begin{abstract}
Resumo
A finalidade deste artigo consiste em apresentar parte dos pressupostos teóricos e metodológic os de uma pesquisa de mestrado. Além disso, procura-se analisar dois dados desta investigação referentes às práticas de revisão e reescrita de alunos do Ensino Médio que participaram de uma oficina de produção de fanfictions realizada no contexto escolar. Nela, os discentes escreveram suas narrativas, as quais foram revisadas por um colega e, posteriormente, reescritas por seus escritores, sendo o corpus constituído pelos textos produzidos por estes sujeitos. Foi constatado que, inicialmente, os estudantes utilizavam-se da revisão e da reescrita considerando somente uma higienização do texto, mas que, no decorrer da prática, tais conceitos foram expandidos e ressignificados.
\end{abstract}

Palavras-chave: fanfictions; escola; revisão; reescrita.

\section{Fanfiction Workshops at School: Investigating Revision and Rewriting Practices}

\begin{abstract}
The purpose of this article is to present part of the theoretical and methodological premises of a master research. This article also seeks to analyze the research data regarding revision and rewriting practices of high school students who participated in a fanfiction production workshop held in the school context. In this workshop, the students wrote their narratives, which were revised by a classmate and subsequently rewritten by their authors. The corpus consists of texts produced by these individuals. It was found that, initially, students revised and rewrote considering only one text cleaning; but with this practice, the concepts of revision and rewriting were expanded and reevaluated.
\end{abstract}

Keywords: fanfictions; school; revision; rewriting.

\section{Introdução}

Este trabalho adota como referência algumas discussões realizadas no decorrer de uma pesquisa de mestrado pertencente à área de Linguística Aplicada. Desse modo, parte da fundamentação teórica e metodológica é apresentada, assim como uma análise de dois dados do corpus. Seu principal objetivo é evidenciar a expansão dos conceitos e sua ressignificação em relação às práticas de revisão e reescrita dos sujeitos desta pesquisa, isto é, alunos do Ensino Médio que realizaram uma oficina de produção de fanfictions na escola. Além disso, também são apontados possíveis diálogos, partindo de uma perspectiva dialógica bakhtiniana, na escrita desses alunos com enunciados do campo do universo escolar, assim como com enunciados do campo de produção e publicação de fanfictions. 
Contudo, é preciso também apresentar algumas justificativas que serviram como motivação e fundamentação para a realização desta pesquisa. A ideia de propor uma oficina de fanfictions no período contraturno ao das aulas regulares relaciona-se com o fato de que jovens estudantes estão cada vez mais se reunindo em espaços on-line com o intuito de ler, escrever, revisar e comentar sobre as fanfictions uns dos outros (BLACK, 2006) em uma situação de produção significativa e contextualizada. Nos websites de produção e publicação de fanfictions, há de fato um posicionamento ativo por parte dos sujeitos escritores e leitores, além do aspecto processual da escrita se fazer presente (BLACK, 2006), considerando que a revisão e a reescrita se constituem como práticas autênticas nesse contexto, conforme é explicitado na próxima seção.

No ambiente escolar, todavia, o cenário se difere, já que a maioria das atividades de produção de texto ainda não é trabalhada considerando uma perspectiva de escrita como prática social e, muitas vezes, é dissociada da realidade do estudante. Nestes casos, os alunos parecem encontrar dificuldades em atribuir sentido à escrita escolar e, quando o fazem, é meramente com o intuito de ser avaliado. Além disso, são raras as situações em que a prática de reescrita se faz presente em atividades de produção textual, sendo assim, a primeira versão de um texto usualmente torna-se a sua versão definitiva (CONCEIÇÃO, 2004).

A revisão, por sua vez, geralmente é realizada apenas pelo professor, diferentemente do universo de publicação de fanfictions, em que os escritores revisam as histórias uns dos outros. Enquanto neste último contexto há, de fato, um interlocutor que se mostra genuinamente interessado no discurso do outro (BLACK, 2006; 2007), na sala de aula, o único interlocutor do aluno, na maioria das vezes, constitui-se pelo e limita-se ao professor. Desse modo, propor a realização de uma oficina de fanfictions na escola busca dialogar com uma prática social pertencente à realidade dos alunos, procurando tornar mais significativas as práticas de revisão e reescrita, especificamente, nas salas de aula.

Em relação à estrutura, este artigo, inicialmente, busca definir e contextualizar a produção escrita de fanfictions (BLACK, 2005; 2006; 2008; 2009), além de relacioná-la à teoria da cultura participativa (JENKINS, 1992; 2006) e dos Novos Letramentos (LANKSHEAR; KNOBEL, 2007; 2011). Em seguida, procura discorrer sobre parte dos pressupostos metodológicos, em que há uma breve contextualização acerca da oficina de produção de fanfictions bem como da metodologia de pesquisa-ação (THIOLLENT, 2011), utilizada para efetivar a geração de dados dessa investigação. Após a apresentação de teoria e metodologia, uma análise de dois dados é realizada, sendo que o primeiro é utilizado como um exemplo que ilustra determinadas revisões e reescritas que se baseavam em uma higienização do texto (JESUS, 1995), enquanto o segundo revela uma expansão e ressignificação de tais práticas. Finalmente, algumas considerações finais são realizadas. 


\section{Contextualizando a produção escrita de fanfictions: pressupostos teóricos}

Fanfictions podem ser definidas, de acordo com Black (2006), como histórias escritas por fãs que possuem como referência, para a sua produção, mídias narrativas e ícones da cultura pop. As histórias podem ser inspiradas em livros, filmes, séries de televisão, animações ou desenhos, letras de música e até mesmo em cantores, bandas, ou atores famosos. Em outras palavras,

[...] fanfiction, ou histórias de autoria de um fã baseadas em conteúdos midiáticos já existentes, é um gênero que se presta a um engajamento crítico em relação aos textos midiáticos na medida em que os fãs redirecionam tais conteúdos para criar suas próprias narrativas. ${ }^{1}$ (BLACK, 2009, p. 76, tradução nossa)

Desse modo, é possível que o fã-autor estenda o enredo original, acrescentando novos acontecimentos à sequência da trama ou situações que precedem o início desta; crie novos personagens, como ao introduzir um novo vilão à narrativa; dê maior ênfase a personagens secundários; ou ainda desenvolva novas relações entre personagens já existentes (BLACK, 2006; 2008). Outro aspecto relevante que pode ser ressaltado em relação a essa prática é o de que grande parte dos autores de fanfictions constitui-se por adolescentes e jovens que ainda estão na escola, mas que produzem essas narrativas de forma voluntária e por desejo próprio fora do ambiente escolar.

Black (2006) ainda afirma que a maioria das fanfictions, atualmente, é publicada em websites de compartilhamento on-line. Neles, é possível que autores e leitores interajam na medida em que a narrativa vai sendo produzida, já que uma prática comum é a de leitores realizarem comentários de feedback ao final de cada capítulo publicado (BLACK, 2006). Muitas vezes, é solicitada e valorizada pelo autor tal interação com seus interlocutores.

Além disso, revisão e reescrita também são frequentemente realizadas no decorrer do processo de produção de fanfictions. É comum que um beta-reader, ou, em outras palavras, um revisor de texto, coloque-se à disposição para revisar uma fanfiction voluntariamente. O escritor, sendo a primeira pessoa a ler a fanfiction, seria o alphareader - ou, ainda, ficwriter, nome pelo qual autores de fanfictions são chamados - e o revisor, suposta segunda pessoa a lê-la, o beta-reader, considerando que alpha e beta são letras do alfabeto grego que indicam a sucessão de elementos.

Os beta-readers, em grande parte das situações, são escritores de fanfictions mais experientes e que, por isso, possuem um olhar mais crítico, o que pode indicar que os próprios escritores colaboram revisando o texto um do outro. Contudo, não é preciso que sejam profissionais da área da linguagem (BLACK, 2005). Assim, a revisão entre os pares - isto é, entre indivíduos situados em uma mesma posição hierárquica - caracteriza-se como mais um recurso disponível para a produção de fanfictions. Em alguns websites de publicação de fanfictions, é comum que os participantes solicitem a um beta-reader a revisão de sua narrativa antes de publicá-la. Logo, tanto a revisão quanto a reescrita, nesse contexto, podem ser compreendidas como práticas autênticas e significativas para seus autores.

\footnotetext{
1 Fanfiction, or fan-authored stories based on existing media, is a genre that lends itself to critical engagement with media texts as fans repurpose these media to create their own narratives.
} 
Há ainda aspectos da produção escrita de fanfictions que se revelam como característicos tanto da teoria da cultura participativa quanto em relação aos conceitos dos Novos Letramentos. De acordo com Jenkins $(1992,2006)$, práticas de letramentos em que a participação do sujeito é essencial cada vez mais se fazem presentes em nossa sociedade. Assim, sujeitos não se restringem a aceitar somente o papel de consumidores, mas desejam ocupar funções de protagonistas ativos em suas diversas experiências sociais. Os fãs, neste sentido, não mais se limitam a apenas posicionarem-se como leitores das narrativas que admiram, tornando-se também escritores de histórias baseadas em seus universos ficcionais. Logo, no contexto de produção e publicação de fanfictions, de acordo com Jenkins, "os fãs deixam de ser simplesmente uma audiência para os textos populares; ao invés disso, eles se tornam participantes ativos na construção e circulação dos sentidos textuais" (JENKINS, 1992, p. 24, tradução nossa).

O autor ainda afirma que, na cultura participativa, cada sujeito possui algo potencialmente interessante que pode ser desenvolvido como uma contribuição para o grupo (JENKINS, 1992). Os papéis sociais, então, são fluidos, por se tratar de uma conjuntura sociocultural flexível, e alternam-se constantemente, pois o mesmo sujeito que ensina em determinada situação pode aprender em outra com o auxílio de um membro diferente (JENKINS, 2006). Assim, um sujeito pode aprender como ficwriter, mas também ensinar como beta-reader e vice-versa.

Já em relação aos chamados Novos Letramentos, Lankshear e Knobel (2011) afirmam que estes podem ser compreendidos como um novo paradigma teórico e de pesquisa, em que uma abordagem alternativa é proposta em relação ao padrão dominante envolvendo os letramentos tradicionais. De acordo com os autores, mudanças vêm ocorrendo em relação ao modo como se constituem as diferentes instituições, mídias e práticas sociais (LANKSHEAR; KNOBEL, 2011), assim como a relação do sujeito com as práticas de leitura e de escrita e suas novas formas de produção.

Para Lankshear e Knobel (2007, 2011), o desenvolvimento das novas tecnologias - em especial, o surgimento da Web 2.0 - proporcionou a expansão e propagação de um novo éthos, ainda que a sua existência não dependa das novas tecnologias e o uso de aparatos digitais e eletrônicos não garanta a produção de Novos Letramentos, já que é preciso haver também a constituição deste novo éthos. Assim, os chamados Novos Letramentos

[...] concentram-se nos modos como as práticas de produção de significado estão evoluindo devido a circunstâncias contemporâneas que incluem - mas não são de forma alguma limitadas a-mudanças tecnológicas associadas ao surgimento e proliferação das tecnologias eletrônicas e digitais ${ }^{3}$ (KNOBEL; LANKSHEAR, 2014, p. 97, tradução nossa).

Este novo éthos, então, possibilita práticas mais participativas, colaborativas, em que o conhecimento distribuído e disperso, a inteligência coletiva, a experimentação e inovação, o ato de compartilhar recursos e conhecimento e, finalmente, a criatividade

\footnotetext{
${ }^{2}$ Fans cease to be simply an audience for popular texts; instead, they become active participants in the construction and circulation of textual meanings.

${ }^{3}$ Focuses on ways in which meaning - making practices are evolving under contemporary conditions that include, but are in no way limited to, technological changes associated with the rise and proliferation of digital electronics.
} 
(LANKSHEAR; KNOBEL, 2007) são consideradas características valorizadas pelos sujeitos cujas práticas se inserem nos Novos Letramentos e que se fazem presentes no contexto de produção e publicação de fanfictions.

\section{Contextualizando a geração de dados: pressupostos metodológicos}

A oficina de produção escrita de fanfictions foi realizada em uma escola pertencente à rede privada de uma cidade do interior do estado de São Paulo, no período contraturno ao das aulas regulares, durante o segundo semestre do ano de 2014. Grande parte dos alunos cursava o primeiro ano do Ensino Médio. A própria pesquisadora também foi responsável por fazer o acompanhamento da oficina como professora. A participação dos estudantes foi voluntária, não havendo atribuição de nota ou acréscimo de pontos nas médias finais da disciplina de Língua Portuguesa.

O objetivo era que os alunos comparecessem à oficina por interesse próprio, desconsiderando a obrigatoriedade tipicamente escolar que há ao se realizar determinadas atividades. Assim, a participação voluntária possuía o intuito de aproximar a oficina de escrita de fanfictions na escola de seu contexto de produção real no ambiente digital, isto é, nos websites de compartilhamento on-line de fanfictions.

Para que a oficina fosse concretizada, cada discente deveria escrever individualmente a sua própria fanfiction - cujo tema e universo ficcional seriam livres para que depois fosse revisada por um colega e, posteriormente, reescrita pelo seu autor. Assim, os participantes ora exerceriam a função de ficwriter (escritor), ora a de betareader (revisor) da narrativa de outro aluno. Com o objetivo de facilitar a revisão dos capítulos e impedir que houvesse limitações em relação ao espaço para a escrita dos comentários, foi utilizada pelos estudantes a ferramenta de revisão presente no processador de texto Word. O corpus para análise, portanto, constitui-se pelos textos produzidos pelos sujeitos participantes da oficina (as primeiras versões das fanfictions, as revisões realizadas a partir delas e as versões reescritas posteriormente).

Levando em consideração tal corpus, esta pesquisa apresenta-se como qualitativa de base interpretativista. A metodologia utilizada constituiu-se pela pesquisa-ação, em que há a intervenção, de acordo com Thiollent (2011), em função da resolução de problemas concretos. Ocorre, assim, a união da pesquisa à prática, com o foco em sua transformação, intervindo em tal prática no decorrer do processo da pesquisa (THIOLLENT, 2011).

Esta metodologia também envolve a participação ativa do pesquisador e dos participantes de modo cooperativo ou participativo (THIOLLENT, 2011) em relação à ação proposta. Neste sentido, a pesquisa-ação não parte de uma pergunta de pesquisa, mas de uma observação palpável da prática. Em relação ao contexto específico desta investigação, é possível notar que a maioria das atividades de produção de texto no ambiente escolar raramente engloba atividades de revisão e reescrita. Nas poucas vezes em que isto ocorre, o usual é que o professor seja o único leitor e revisor do texto do aluno e este último, ao receber sua produção revisada, geralmente não a reescreve.

Assim, ao fazer uso da pesquisa-ação, o intuito é o de buscar transformar e ressignificar as práticas de revisão e reescrita dos alunos participantes da oficina por meio da interferência da professora/pesquisadora, mas, também, e principalmente, por meio da intervenção dos discentes na fanfiction individual de seus colegas. Desse modo, os 
próprios alunos são sujeitos ativos fundamentais e socialmente representativos de tal transformação.

\section{Analisando práticas de revisão e reescrita de fanfictions}

Em parte das revisões e reescritas realizadas pelos alunos participantes da oficina de fanfictions, foi possível constatar que houve a intenção de efetuar uma higienização do texto (JESUS, 1995). De acordo com Jesus (1995), a prática de reescrita no contexto escolar é, muitas vezes, trabalhada a partir de um enfoque higienizador da linguagem, em que há a busca por tornar um texto transparente por meio de uma homogeneidade linguística, obedecendo-se a um modelo-padrão previamente estabelecido. Desse modo, os desvios gramaticais acabam por se sobrepor aos outros aspectos do texto, sendo atribuída uma maior importância à ortografia, à pontuação e à concordância, tal como revela Jesus (1995), em detrimento do repertório semântico da produção e da formulação do dizer do aluno enquanto enunciador. Neste sentido, revisão e reescrita são entendidas como uma espécie de "operação limpeza" (JESUS, 1995). Vejamos o exemplo para, em seguida, apresentar ponderações sobre ele.

(1)

\section{Primeira versão}

Ele resolve ir viver junto com seus amigos na Inglaterra, pensa, mas não está decidido a ir morar lá. Faz-se perguntas o tempo todo. Onde irá morar? Irá voltar a crecer, era aquilo mesmo que queria? Largaria aquele lugar para ir viver em outro "mundo"?

Estava confuso, resolveu ir falar com a sabia dos índios Peles Vermelhas, e tentar resolver algo naquela confusão que estava a sua cabeça. Após ter conversado com ela,

\section{Revisão}

Ele resolve ir viver junto com seus amigos na Inglaterra, pensa, mas não está
decidido a ir morar lá. Faz-se perguntas o tempo todo. Onde irá morar? Irá voltar a crecer),
era aquilo mesmo que queria? Largaria aquele lugar para ir viver em outro "mundo"?
Estava confuso, resolveu ir falar com a sabial dos índios Peles Vermelhas[|, e tentar
resolver algo naquela confusão que estava a sua cabeça. Após ter conversado com ela,




\section{Reescrita}

Ele resolve ir viver junto com seus amigos na Inglaterra, pensa, mas não está
decidido a ir morar lá. Se faz perguntas o tempo todo. Onde irá morar? Irá voltar a
crescer, era aquilo mesmo que queria? Largaria aquele lugar para ir viver em outro
"mundo"?
Estava confuso, resolveu ir falar com a sábia dos índios Peles Vermelhas e tentar
resolver algo naquela confusão que estava a sua cabeça. Após ter conversado com ela,

No exemplo de número um, apresento a versão inicial de um trecho do primeiro capítulo de uma fanfiction de uma aluna participante, seguida da revisão realizada por uma colega também da oficina, finalizando com a reescrita desse mesmo trecho por sua escritora. Essa revisão revela-se interessante, considerando-se que quatro correções seguidas foram realizadas com o foco de "higienizar" o texto. A beta-reader indica que "crescer" escreve-se com "sc" e "sábia" possui acento agudo na primeira sílaba (ambos desvios ortográficos). A aluna também adverte que não existe a necessidade de pontuar o texto com vírgulas quando há o uso da conjunção "e" (inadequação relacionada à pontuação). Por fim, a revisora assinala que, em sua visão, o pronome átono "se" deveria preceder o verbo "fazer". Contudo, de acordo com a norma padrão da língua portuguesa, é a ênclise que deveria, de fato, ser utilizada quando o verbo inicia uma oração, sendo correto, segundo essa perspectiva, o modo como a ficwriter havia escrito anteriorme nte em sua primeira versão ("Faz-se"). Na reescrita, a escritora, por sua vez, modifica aquilo que foi apontado como problema na revisão, inclusive o que inicialmente estava adequado de acordo com a norma.

Desse modo, embora nem sempre adequada à norma padrão, a beta-reader realiza revisões que buscam uma melhoria meramente gramatical em detrimento de possíveis aprimoramentos relacionados a outros aspectos textuais e discursivos. Além disso, a partir de uma perspectiva dialógica bakhtiniana e tomando como base o exemplo de número um, é possível afirmar que parte das revisões higienizadoras de alguns alunos betareaders, participantes da oficina, possivelmente dialogou com enunciados relacionados às práticas de revisão de texto escolarizadas. É provável que esta aluna tenha compreendido que a sua revisão deveria ser efetuada de modo similar às correções feitas por diferentes professores em seus textos durante grande parte de sua vida estudantil, já que a oficina situou-se no ambiente escolar. Isto pode se constituir como um indício de diálogo com o modo como a maioria das revisões textuais é realizada na escola, já que, segundo Jesus (1995), tal enfoque higienizador manifesta-se, frequentemente, nas correções efetuadas pelos docentes.

No decorrer da oficina de fanfictions, os conceitos relacionados às práticas de revisão e reescrita foram reconstruídos e ressignificados devido às intervenções tanto da professora/pesquisadora quanto dos próprios alunos nas narrativas uns dos outros. A higienização do texto, portanto, deixa de ser o foco dos alunos. Vejamos o segundo exemplo a seguir, em que apresento somente a revisão por tratar-se de um comentário final visando melhorias no capítulo como um todo. Assim, não seria possível, pela limitação de espaço, expor neste artigo tanto a primeira versão do capítulo completo quanto a sua reescrita. 
(2)

\section{Revisão}

\begin{tabular}{|c|c|c|}
\hline \multicolumn{2}{|c|}{$\begin{array}{l}\text { para eu ir buscá-la, e não ele. Acho que tenho que preparar um pedido decente de } \\
\text { (desculpas... }\end{array}$} & \multirow{2}{*}{ 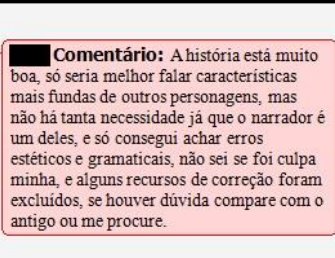 } \\
\hline & \multirow{2}{*}{$\begin{array}{l}\text { A história está muito boa, só seria melhor falar } \\
\text { características mais fundas de outros } \\
\text { personagens, mas não há tanta necessidade já } \\
\text { que o narrador é um deles, e só conseguiachar } \\
\text { erros estéticos e gramaticais, não sei se foi } \\
\text { culpa minha, e alguns recursos de correção } \\
\text { foram excluídos, se houver dúvida compare } \\
\text { com o antigo ou me procure. }\end{array}$} & \\
\hline & & \\
\hline
\end{tabular}

O exemplo de número dois é particularmente interessante por revelar diálogos com enunciados produzidos por outros participantes da oficina de fanfictions. Algumas revisões realizadas pelos alunos demonstravam, conforme já dito anteriormente, priorizar correções higienizadoras em detrimento daquelas que visassem um aprimoramento dos outros elementos tanto das convenções da escrita quanto em relação à adequação ao gênero, por exemplo. Considerando que intervenções do professor também se constitue m como parte de uma pesquisa-ação, decidi realizar uma atividade de revisão coletiva com os alunos para que eles pudessem expandir e reconstruir suas visões acerca da revisão e reescrita por meio de reflexões sobre tais práticas

Assim, durante a atividade, revisões coletivas foram realizadas em uma fanfiction que também tivessem como foco outros aspectos do texto. O intuito da atividade era o de proporcionar um debate com os alunos acerca daquilo que eles entendiam como adequado em relação às suas funções como revisores. O grupo chegou à conclusão de que os betareaders não deveriam se manter restritos às revisões gramaticais relacionadas a uma adequação à norma padrão da língua, uma vez que era relevante observar a coerência da narrativa, por exemplo, entre outros aspectos ressaltados pelos discentes.

Após esta discussão do grupo, é possível que o aluno revisor do exemplo de número dois tenha compreendido que seus colegas valorizavam as revisões não higienizadoras, devido ao discurso efetuado na atividade coletiva. Assim, em um comentário metalinguístico, o beta-reader se desculpa justamente por não ter sido capaz de realizar aquilo que havia sido acordado pelo grupo na atividade coletiva ("e só consegui achar erros estéticos e gramaticais, não sei se foi culpa minha").

Logo, o fato de ter revisado apenas "erros estéticos e gramaticais" - isto é, higienizadores - iria contra o que os participantes da oficina haviam sugerido, fazendo com que o aluno não concretizasse, em sua revisão, aquilo que foi considerado pelo grupo como adequado para essa função. O comentário do beta-reader também revela que ele possui consciência de que algumas de suas correções se caracterizaram por apresentar um enfoque higienizador, apesar de ainda efetuá-las desse modo. Por isso, esse comentário já demonstra uma mudança de perspectiva do aluno em relação ao conceito de revisão, pois, metalinguisticamente, ele foi capaz de perceber que há diferentes formas de revisar um texto, ampliando e ressignificando, assim, sua noção anterior acerca da prática de revisão. 
Além disso, é possível notar, a partir desse comentário, que, além de realizar críticas para que o escritor procure efetuar melhorias em sua fanfiction, o revisor também elogia a narrativa com o intuito de ressaltar aspectos positivos ("a história está muito boa"). Assim, o ficwriter compreende que há partes que precisam ser aprimoradas, mas também é reconhecido nos trechos em que fez um bom trabalho. A revisão, nestes casos, não se relaciona somente a um viés higienizador ou negativo e, ainda, por meio dos elogios, pode incentivar o escritor a aprimorar sua fanfiction.

Assim sendo, neste caso, é provável que haja também diálogos com enunciados do campo de produção e publicação de fanfictions. Tanto traços da cultura participativa - como a manifestação de elogios para motivar o sujeito a continuar participando do grupo ou da comunidade - quanto dos Novos Letramentos - por meio de práticas mais colaborativas, como a revisão entre pares, por exemplo - estão presentes no comentário do exemplo de número dois. Além disso, as correções não se limitaram a apontar somente aspectos gramaticais e higienizadores do texto, como de fato ocorreu no primeiro exemplo, já que o revisor também sugere a melhoria em relação à caracterização das personagens, aproximando-se do modo como grande parte dos comentários é realizada nos websites de produção e publicação de fanfictions.

\section{Considerações finais}

A partir dos dados analisados na seção anterior, foi possível evidenciar indíc ios de diálogos com enunciados tanto relacionados às práticas escolarizadas quanto àquelas realizadas no contexto de produção de fanfictions. De acordo com Pinheiro (2013), é necessário, na escola, dialogar com práticas sociais ligadas à realidade do aluno, a fim de que a construção do conhecimento se torne situada para o discente. Assim, pode ser interessante propor, nas salas de aulas, atividades de escrita de fanfictions, dentre outras alternativas possíveis, considerando que se trata de um gênero discursivo que incentiva a participação ativa do sujeito, a interação entre interlocutores, bem como o emprego de revisões entre pares e reescritas que já estão presentes em seu contexto original.

Assim, por meio de práticas situadas que possuem propósitos e interlocutores autênticos, talvez seja possível que alguns alunos passem a atribuir maior sentido à revisão e à reescrita, não se limitando a escrever, revisar e reescrever visando somente uma "operação limpeza". Para Jesus (1995), grande parte das atividades de produção textual na escola ainda possui como foco apenas atingir um padrão de escrita considerando critérios gramaticais decorrentes de uma higienização do texto. A autora alega que essa abordagem pode obter um texto linguisticamente correto, mas que ignora as relações de sentido emergentes na interlocução (JESUS, 1995), além de não objetivar melhorias em relação a aspectos discursivos da escrita. O potencial de realização do texto, desse modo, pode ser prejudicado, bem como as relações de coesão e coerência, embora a produção esteja de acordo com a norma padrão da língua portuguesa.

Entretanto, embora seja comum, na escola, objetivar esta "operação limpeza", os dados analisados neste artigo indicam que é possível expandir a noção dos alunos referente à revisão e à reescrita, compreendidas somente como uma higienização do texto, ressignificando aquilo que os discentes entendem em relação a tais práticas. No exemplo analisado, o estudante revisor se justifica, metalinguisticamente, por ter sugerido apenas modificações gramaticais, demonstrando ter consciência de que não era preciso se limitar a esse aspecto. $\mathrm{O}$ aluno, apesar de ainda realizar revisões visando uma higienização do 
texto, também sugeriu modificações em relação à construção de personagens, revelando ter ampliado aquilo que julga relevante ser reelaborado na reescrita.

Em síntese, a produção de fanfictions na escola pode auxiliar os jovens escritores a aprimorar diversas habilidades e competências da escrita requeridas no ambiente escolar (BLACK, 2005). A produção de gêneros discursivos narrativos que possuem propósitos claros e significativos, a presença de leitores e interlocutores genuinamente interessados, além de um engajamento em práticas de revisão (entre os pares) e de reescrita autênticas constituem-se apenas como algumas das características da situação de produção de fanfictions que podem ser aproveitadas nas salas de aula. Além disso, trabalhar com as fanfictions pode promover também o acesso desses jovens a práticas de letramentos digitais (BLACK, 2005), cada vez mais solicitadas por serem compreendidas como essenciais para uma participação plena em diferentes situações sociais, acadêmicas e profissionais. Finalmente, de acordo com Black (2009), é preciso considerar que grande parte das fanfictions é escrita voluntariamente por adolescentes que dedicam horas do seu tempo lendo, escrevendo e comentando nos websites de publicação dessas histórias, mas que não possuem a mesma motivação e engajamento para a realização de atividades de produção escrita no espaço escolar. Desse modo, pode ser interessante para o contexto escolar realizar atividades de produção textual que evidenciem a natureza social e participativa da escrita (BLACK, 2006), como o faz a produção de fanfictions.

\section{REFERÊNCIAS}

BLACK, R. Access and affiliation: the literacy and composition practices of Englishlanguage learners in an online fanfiction community. In: Journal of adolescent \& adult literacy, v.49, n.2, p. 118-128, 2005. DOI: 10.1598/JAAL.49.2.4.

Language, Culture, and Identity in Online Fanfiction. In: E-Learning, v.3, n.2, p. 170-184, 2006. DOI: 10.2304/elea.2006.3.2.170.

Digital Design: English Language Learners and Reader Reviews in Online Fiction. In: KNOBEL, M.; LANKSHEAR, C. A new literacies sampler. New York: Peter Lang, 2007. p. 115-136.

Just don't call them cartoons: the new literacy spaces of anime, manga, and fanfiction. In: LEU, J. D.; COIRO, C.; LANKSHEAR, C.; KNOBEL, M. (orgs.). Handbook of research on new literacies. Mahwah, NJ: Erlbaum, 2008. p. 587-615.

Online fanfiction and critical media literacy. In: Journal of Computing in Teacher Education, v.26, n.2, p. 75-80, 2009. DOI: 10.1080/10402454.2009.10784636.

CONCEIÇÃO, R. I. S. Correção de texto: um desafio para o professor de português. In: Trabalhos em Linguística Aplicada, v.43, n.2, p. 323-344, jul./dez. 2004. DOI: 10.1590/S0103-18132004000200001.

JENKINS, H. Textual Poachers: television fans and participatory culture. New York: Routledge, 1992.346 p.

Convergence culture: where old and new media collide. New York: New York University Press, 2006. 308 p. 
JESUS, C. A. de. Reescrita: para além da higienização. 1995. 125 p. Dissertação (Mestrado em Linguística Aplicada). - Instituto de Estudos da Linguagem, Universidade Estadual de Campinas, Campinas.

KNOBEL, M.; LANKSHEAR, C. Studying New Literacies. In: Journal of Adolescent \& Adult Literacy, v.58, n.2, p. 97-101, 2014. DOI: 10.1002 /jaal.314.

LANKSHEAR, C.; KNOBEL, M. Sampling "the new" in New Literacies. In: KNOBEL, M.; LANKSHEAR, C. (orgs.). A new literacies sampler. New York: Peter Lang, 2007. p. $1-24$.

New literacies: everyday practices and social learning. Berkshire, New York: Open University Press, 2011. 280 p.

PINHEIRO, P. A. Gêneros no mundo digital: um meio de "transdisciplinar" a escola. In: GONÇALVES, A. V.; BAZARIM, M. (orgs.). Interação, gêneros e letramento: a (re)escrita em foco. 2. ed. Campinas: Pontes Editores, 2013. p. 221- 235.

THIOLLENT, M. Metodologia da pesquisa-ação. 18. ed. São Paulo: Cortez, 2011, 136 p.

Recebido em: 08/09/2015

Aprovado em: 16/03/2016 